\title{
PREDICTORS OF CLINICAL RESPONSE TO CLOZAPINE IN TREATMENT RESISTANT SCHIZOPHRENIA
}

\section{A Aissa ${ }^{1}, \mathbf{R}$ Jouini' ${ }^{1}$, A Larnaout ${ }^{1}$, F Ellouze ${ }^{2}$, H Ben Ammar ${ }^{1}$, E Khelifa ${ }^{1}$, F Nacef ${ }^{3}$, Z El Hechmi ${ }^{1}$}

\section{F Psychiatry Department, Razi Hospital, University Tunis El Manar, Tunisia \\ 2. Psychiatry Department, Military Hospital, Tunis, Tunisia 3. A Psychiatry Department, Razi Hospital, University Tunis El Manar, Tunisia}

\section{INTRODUCTION}

Clozapine is the treatment of choice in resistant schizophrenia. In practice, therapeutic decision to initiate treatment with clozapine is often difficult to take, because of its adverse effects requiring strict periodic monitoring. There is a clinical need to identify factors associated with a good response to clozapine during resistant schizophrenia

The aim of this study was aim to investigate predictors of response to clozapine during resistant schizophrenia.

\section{MATERIALS AND METHODS}

We conducted a cross-sectional study, in two psychiatric departments "A" and "F" of Psychiatric Razi hospital in Manouba, Tunisia and included 57 patients with treatment resistant schizophrenia (TRS). We investigated clinical clozapine response using BPRS. We dichotomously categorized our population into two groups: clozapine responders with BPRS total scores equal to or less than 35 and clozapine non responders with a BPRS score above 35 .

For clinical response predictors we investigated: Childhood Traumatic events using the Childhood Trauma Questionnaire (CTQ) scale, Premorbid adjustment scale (PAS) and demographic, clinical characteristics and profile treatment

\section{RESULTS}

The mean age was 37.1 ans \pm 9.2. The sex ratio was 2.8.

Paranoid schizophrenia was significantly associated with good clinical response $(p=0.029)$.
A better clinical response was associated with an emotional neglect score $>0.72$, CTQ total score $\leq 0,40 \quad(p=0.038)$ and social functioning during childhood $\leq 0.25(p=0.029)$ and during first adolescence $<0.27(p=0.03)$.

\begin{tabular}{|l|c|}
\hline Mean duration of illness & 15.8 years \\
\hline Duration of untreated psychosis & 15.9 months \\
\hline $\begin{array}{l}\text { Mean illness duration at clozapine } \\
\text { introduction }\end{array}$ & 8.9 years \\
\hline Mean clozapine dose per day & $396,4 \mathbf{m g} \pm \mathbf{1 1 4 , 2}$ \\
\hline $\begin{array}{l}\text { Childhood Trauma rate (CTQ) } \\
(>0,41 \pm 0,04)\end{array}$ & $49 \%$ \\
\hline $\begin{array}{l}\text { Premorbid adjustment rate (PAS) } \\
(<0,36 \pm 0,14)\end{array}$ & $37 \%$ \\
\hline
\end{tabular}

\section{DISCUSSION}

Female gender, earlier age of onset, non-paranoid subtype, longer duration of illness, baseline psychopathology, baseline quality of life, serum clozapine levels below $350 \mathrm{ng} / \mathrm{ml}$ and poor functioning during the previous year have already been reported as the potential clinical predictors of non-response to clozapine (1). Our results suggest the importance of adequate premorbid adjustment and the absence of childhood trauma in clozapine response.

\section{CONCLUSION}

Our study has shown the importance of premorbid and clinical parameters in predicting clinical response to clozapine in patients with TRS in order to optimize therapeutic management
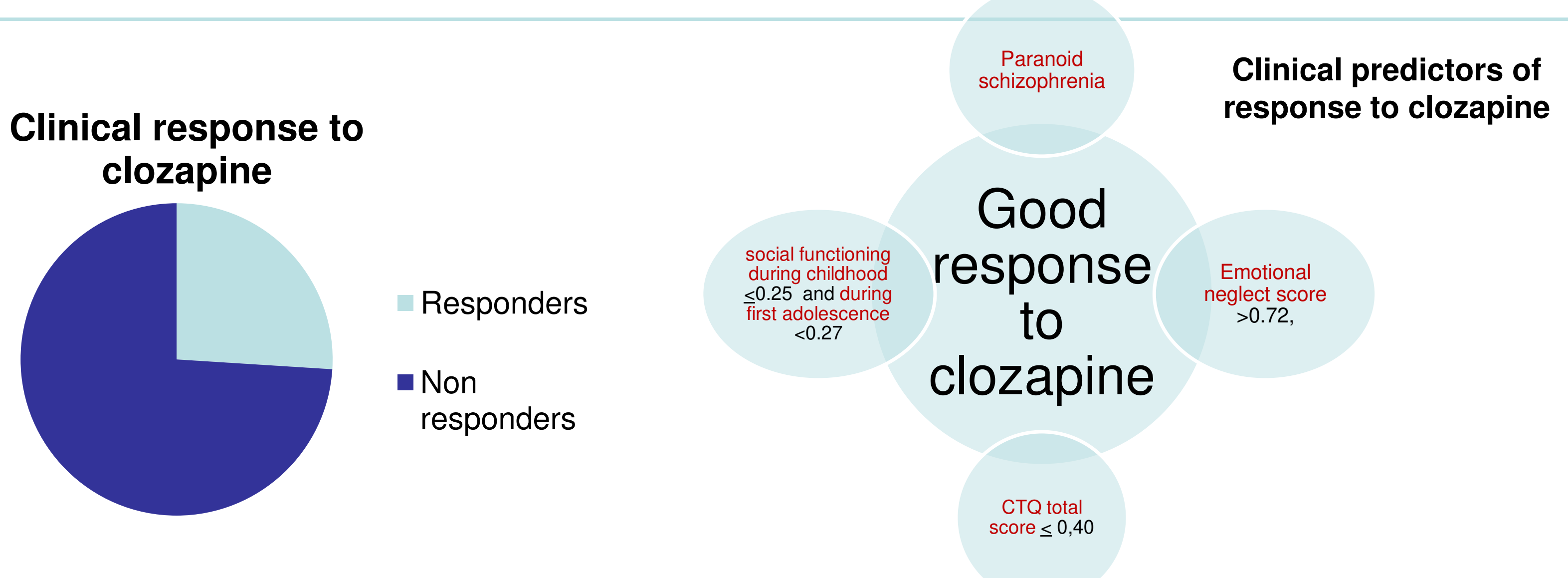

1 Rajkumar AP, Chitra C, Bhuvaneshwari S, Poonkuzhali B, Kuruvilla A, Jacob KS. 